\title{
Laparoscopic versus open appendectomy in treatment of acute appendicitis
}

\author{
Oravsky M, Bak V, Schnorrer M \\ 3rd Department of General Surgery, Medical Faculty, Comenius University Bratislava, Slovakia. \\ moravsky@milosrdni.sk
}

\begin{abstract}
Introduction: The authors present the results of a retrospective study comparing the laparoscopic and open procedures of appendectomy for the diagnosis of acute appendicitis.

Material and methods. Retrospective analysis of the results of both methods on a set of 161 patients in period 2006-2010.

Results: Regarding the intraabdominal complications and hospitalization periods, results confirm the equivalence of both methods. A significantly lower incidence of wound complications as well as shorter hospital stay were experienced in the laparoscopy-treated group of patients.

Conclusion: Based on the results of this study, the laparotomic appendectomy would be reserved for appendicitis with diffuse peritonitis. The laparoscopy is positively preferred in obese patients (Tab. 3, Ref. 16). Text in PDF www.elis.sk.

Key words: acute appendicitis, laparoscopic appendectomy.
\end{abstract}

In the pre-antibiotic era, there was no option of conservative treatment of acute appendicitis. At present time the cases of noncomplicated appendicitis can be treated also by antibiotics, which can eliminate the necessity of surgery $(1,2)$. From the surgical standpoint, appendectomy remains the gold standard (1), but the method of choice is still unclear. Laparoscopic appendectomy is not a standard method of first choice for the treatment of acute appendicitis unlike laparoscopic cholecystectomy for cholecystolithiasis. Although many studies have confirmed equivalent results compared to McBurney's open appendectomy technique in the right hypogastrium, these studies did not take account of the known advantages of laparoscopy, such as shorter hospital stays, lower consumption of analgesics, shorter sick leave (3-6). Our study retrospectively evaluates the postoperative complications in patients with acute appendicitis treated with laparoscopic or open appendectomy.

\section{Patients and results}

A retrospective review of 161 patients diagnosed with acute appendicitis treated by appendectomy was performed at 3rd Clinic of Surgery, Bratislava University Hospital in years from 2006 to 2010. Eighty-one patients were females and 80 were males. The mean age of patients treated with laparotomy was 33 years while that of laparoscopy-treated group was 34 years (Tab. 1). The op-

3rd Department of General Surgery, Medical Faculty, Comenius University Bratislava, Slovakia

Address for correspondence: M. Oravsky, MD, 3rd Department of General Surgery, Medical Faculty, Comenius University Bratislava and UN MB, Namestie SNP 10, SK-814 65 Bratislava, Slovakia.

Phone: +421.2.57887401 erative approach was based on the surgeon's decision. The open appendectomy was performed using McBurney's technique with the incision made in the right hypogastrium area. After excising the appendix, the appendiceal stump was inverted using a Z-suture or purse-string suture. Laparoscopy was performed using three ports including the laparoscope and two working instruments. The appendiceal stump was ligated by a hand-made Roeder's loop using Vicryl without the following inversion. Antibiotics were not routinely used. Our results were evaluated retrospectively. The number of open appendectomies performed was higher in the first year of our study. Later on, the number of laparotomies was decreasing, and laparoscopic appendectomy has become the treatment of choice in acute appendicitis.

In both treated groups of patients the pathological findings showed the predominance of the phlegmonous appendicitis (Tab. 2). Eight times, the laparoscopic operation was converted to laparotomy. In two patients, the cause of conversion was peri-appendiceal infiltration and in six of them the conversion took place

Tab. 1. Number of performed appendectomies in different years.

\begin{tabular}{lcc}
\hline Year & Open appendectomy & Laparoscopic appendectomy \\
\hline 2006 & 21 & 14 \\
2007 & 16 & 18 \\
2008 & 5 & 25 \\
2009 & 6 & 26 \\
\hline 2010 & 3 & 27 \\
\hline
\end{tabular}

Tab. 2. Pathological findings of appendicitis.

\begin{tabular}{lccc}
\hline Appendicitis & Catarrhalis & Phlegmonosa & Gangrenosa \\
\hline Open Appendectomy & 11 & 28 & 12 \\
Laparoscopic Appendectomy & 13 & 79 & 18 \\
\hline
\end{tabular}


Tab. 3. Occurrence of post-operative complications.

\begin{tabular}{lcc}
\hline Post-operative complication & Wound abscess & Intra-abdominal abscess \\
\hline Open appendectomy & 11 & 4 \\
Laparoscopic appendectomy & 5 & 8 \\
\hline
\end{tabular}

due to progression of inflammatory changes and perforation of the appendix with local peritonitis.

The mean length of hospital stay of laparoscopy-treated patients was 2.7 days (in range from 2 to 9 days), and that of laparotomy-treated patients was 3.3 (in range from 2 to 19 days).

Two of the patients after laparoscopy were re-operated due to clinical sings of peritonitis. In the first case, an assumption that the ligature has slipped from the appendiceal stump was not confirmed. The local peritoneal sings were caused by remaining inflammation of the peritoneum from previous ulcero-phlegmonous appendicitis. Afterwards the patient underwent conservative medical therapy and was discharged from the hospital on the 8th post-operative day. In the second case, the re-operation was performed by laparotomy due to a formation of intra-abdominal abscess on the 4th post-operative day. In six days after the laparotomy, the patient was discharged from the hospital in good condition.

Only one case of re-operation was performed after open appendectomy. The patient was re-operated on the same day of appendectomy due to hemoperitoneum caused by slipping of ligature from the appendicular artery. In the post-operative period, the patient was stabilized and subsequently discharged from hospital on the fourth post-operative day. Other complications did not require surgery (Tab. 3).

\section{Discussion}

Comparison of the open and laparoscopic methods of appendectomy in the treatment of acute appendicitis was analyzed in many studies. The results of some works have noticed well-known advantages of laparoscopy such as lower consumption of analgesics, shortening of hospital stay, lower incidence of wound and intra-abdominal complications and shortening of sick leave (7-10). Most prospective studies showed the same results in both surgical approaches. In the laparotomy group, the only complication with a significantly higher incidence was wound infection (11-13).

The value of our results in evidence-based medicine is limited due to retrospective character of the study. The main focus was on the early post-operative complications. In terms of wound complications, there was higher incidence in patients who underwent the open appendectomy. A wound abscess was observed in 11 patients (23\%). Most wound complications were observed during postoperative out-patient checkups, because once their postoperative condition became stable, these patients were usually discharged from hospital on the second or third post-operative day. The wound complications did not prolong the hospital stay. All 11 patients visited the surgical out-patient clinic for a prolonged period of time. In the group of patients who underwent laparoscopic appendectomy, wound abscess was observed in five patients.

The wound abscess occurred only in place through which the appendix was extracted from the abdominal cavity via a $10 \mathrm{~mm}$ - wide laparoscopic sleeve. After the operative technique had been modified using the 25-mm laparoscopic sleeve called Kleiber, we did not encounter any wound inflammation. All wound abscesses were detected at the out-patient clinic. The comparison of wound infection in the laparoscopic and open appendectomy groups turned out to be unequivocally in favor of the laparoscopy group. If the wound abscess occurs, the risk of hernia is greater after laparotomy $(14,15)$.

Infiltration or intra-abdominal abscess in the right hypogastrium was diagnosed using ultrasonography or CT scan in eight patients after laparoscopic appendectomy in complicated appendicitis. Their occurrence has been ascribed to the inflamed mesoappendix remaining in the abdominal cavity. All patients underwent conservative medical management, and were treated with antibiotics. Only one patient with an intra-abdominal abscess was re-operated on the forth post-operative day. Two days later, he was discharged from hospital with antibiotics therapy. Based on our experience, we perform laparoscopic appendectomy including the removal of inflamed meso-appendix. In case of exudates, tubular drainage is placed into the Douglas's space. The mean hospital stay was shorter for laparoscopy but the difference was not significant.

Based on our results we incline to perform the laparoscopic appendectomy when treating acute appendicitis. Even though the intra-operative findings of the local infiltration or peritonitis with exudate might be a risk for the performance of laparoscopic appendectomy, it gives the advantage for targeted laparotomy (14). In case of local peritonitis we tend to perform a lower medial laparotomy that allows sufficient operative approach in the lower parts of the abdominal cavity with adequate peritoneal lavage and drainage.

\section{Conclusion}

In general, laparoscopic appendectomy has not gained widespread acceptance at our surgical departments. Most of the published works show the equivalence of both methods. Based on our experience, we prefer the laparoscopic appendectomy due to the lower risk of wound complication and shorter work leave. The main advantage is its use in obese patients. In conclusion, the decision about surgical approach to acute appendicitis, is the right and responsibility of the operating surgeon, and is usually influenced by experience and habits developed by the surgeon, as well as adopted by department as a whole.

\section{References}

1. Vons C, Barry C, Maitre S et al. Amoxicillin plus clavulanic acid versus appendicectomy for treatment of acute uncomplicated appendicitis: an open-label, non-inferiority, randomized controlled trial. Lancet 2011; 377: 1573-1579.

2. Allescher HD. Appendicitis: can immediate antibiotic treatment still be withheld? Selected summaries. Gastroenterology 2012; 142: 666-669.

3. Vettoretto N, Gobbi S. Consensus conference on laparoscopic appendectomy: development of guidelines. Colorect Dis 2011; 13: 748-754. 


\section{$660-662$}

4. Shirazi B, Ali N, Shamin MS. Laparoscopic versus open appendectomy: a comparative study. J Pak Med Assoc 2010; 60: 901-904.

5. Yeh CC, Wu SC, Lai HW et al. Laparoscopic appendectomy for acute appendicitis is more favorable for patients with comorbidities, in erderly and those with complicated appendicitis. Surg Endosc 2011; 18: 125-129.

6. Wu HS, Lai HW, Kuo S et al. Comparative edge of laparoscopic appendectomy versus open appendectomy. J Laparoendosc Adv Surg Tech 2011; 21: 197-202.

7. Strzalka M, Bobrzinsky A, Budzynski A et al. Open or laparoscopic appendectomy? Videosurgery and other miniinvasive techniques 2009; 4: 10-114.

8. Swank HA, Eshuis EJ, Van Berge Henegouwen MI et al. Short and long term results of open versus laparoscopic appendectomy. World J. Surg 2011; 35: 1221-1226.

9. Liu Z, Zhang P, Ma Y et al. Laparoscopy or not:a meta analysis of the surgical effects of laparoscopic versus open appendectomy. Surg Laparosc Endosc Percutan Tech 2010; 20: 362-370.
10. Wu SC, Wang YC, Fu CY et al. Laparoscopic appendectomy provides better outcomes than open appendectomy in elderly patients. Am Surg 2011; 77: 446-470.

11. Moazzez A, Maso RJ, Kathkouda N. Laparoscopic appendectomy: new concepts. World J Surg 2011; 35: 1515-1518.

12. D Ambra L, Berti S, Bonfante $P$ et al. Laparoscopic appendectomy for complicated acute appendicitis. G Chir 2011; 32: 181-184.

13. Khiria LS, Ardhnari R, Mohan N et al. Laparoscopic appendectomy for complicated appendicitis: is it safe and justified? Surg Laparosc Endosc Percutan Tech 2011; 21: 142-145.

14. Asarias JR, Schlussel AT, Cafasso DE et al. Incidence of postoperative intraabdominal abscesses in open versus laparoscopic appendectomies. Surg Endosc 2011; 18: 2678-2683.

15. Clarke T, Kathkouda N, Mason RJ et al. Laparoscopic versus open appendectomy for the obese patient. Surg Endosc 2011; 18: 1279-1280.

16. Kim MJ, Fleming FJ. Laparoscopic appendectomy is safe and efficacious for the elderly. Surg Endosc 2011; 18: 1802-1807.

Received April 30, 2012. Accepted March 15, 2014. 